\title{
A COGESTÃO NO SISTEMA PENITENCIÁRIO DO RIO GRANDE DO NORTE:
} LIMITES E CONTRIBUIÇÕES

\author{
Jordaline Rayne Santos Melo ${ }^{1}$ \\ Richard Medeiros Araújo ${ }^{2}$
}

\begin{abstract}
RESUMO: As discussões acerca da crise que permeia o Sistema Prisional norte riograndense só têm aumentado nos últimos anos. Aponta-se a ineficiência do Estado na gestão das prisões em contrapartida a eficiência da iniciativa privada. Associado a isso o Estado brasileiro vem delegando cada vez mais a provisão dos seus serviços à entes privados e na esteira desse novo modelo de gestão da coisa pública é cada vez mais frequente a gerência de serviços prisionais sob o comando de empresas particulares. Os defensores desse modelo de gestão compartilhada buscam fundamentação nos modelos norte-americanos e francês, países esses que investem milhões em sistema carcerário, enquanto o RN pouco injeta recursos que priorizem a (re)integração do interno ao convívio social. Assim como maneira de discutir sobre novas ferramentas para a elaboração de políticas públicas para o sistema prisional do $\mathrm{RN}$, o trabalho de revisão bibliográfica em livros e artigos busca proporcionar reflexões a respeito da contribuição desse novo modelo de provisão de operação de serviços prisionais, bem como seus limites na construção da política carcerária no RN.
\end{abstract}

Palavras-chaves: Sistema Prisional. Cogestão Compartilhada. Políticas Públicas.

\section{CO-MANAGEMENT IN THE PENITENTIARY SYSTEM OF RIO GRANDE DO NORTE: LIMITS AND CONTRIBUTIONS}

ABSTRACT: Discussions about the crisis that permeates the northern prison system have only increased in recent years. It points out the inefficiency of the State in the management of prisons in counterpart to the efficiency of private initiative. Associated with this, the Brazilian State has been increasingly delegating the provision of its services to private entities and, in the wake of this new model of public management, more and more frequently the management of prison services under the control of private companies. The proponents of this shared management model seek to provide a basis for the US and French models, which invest millions in the prison system, while the $\mathrm{RN}$ does little inject resources that prioritize the

\footnotetext{
${ }^{1}$ Especialista em Gestão Pública. Universidade Federal do Rio Grande do Norte. Rio Grande do Norte. Brasil. E-mail: jordalinerayane@yahoo.com.br

${ }^{2}$ Doutor em Administração. Universidade Federal do Rio Grande do Norte. Rio Grande do Norte. Brasil. E-mail: richardmaraujo@uol.com.br
}

Ágora: R. Divulg. Cient., v. 22, n. 1, p. 87-103, jan./jul. 2017 (ISSNe 2237-9010) 
reintegration of the inmate into social interaction. As a way of discussing new tools for the elaboration of public policies for the prison system of the newborn, the work of bibliographical revision in books and articles seeks to provide reflections on the contribution of this new model of provision of prison services operation, as well as Its limits in the construction of the prison policy in the RN.

Key-words: Prison System. Shared Co-management. Public policy.

\section{INTRODUÇÃO}

Os padrões de relacionamento entre Estado e sociedade têm passado por significativas mudanças nas últimas décadas. O campo de atuação direta do Estado sobre os serviços públicos introduz novos instrumentos e finalidades, fortalecendo uma noção diversa de como deve ser ofertado tais serviços.

Essa nova perspectiva impacta na forma de provisão dos serviços públicos, quando quebram o monopólio estatal na prestação dessas atividades, abrindo-as ao processo de privatização. Anterior a isso, o Estado manifestava-se assumindo diretamente a produção de bens e serviços, além de limitar, regrar e normatizar as atividades de diversos setores (MORAES NETO, 2002).

A reorganização do papel do Estado frente as demandas públicas tem mostrado uma redução expressiva em sua intervenção, transferindo a execução de funções tradicionalmente providas pelo governo, como nos setores de saúde, exploração de recursos hídricos, transporte à iniciativa privada.

A transformação do modelo de intervenção estatal sobre a prestação de serviços públicos não é um tema novo. Entretanto, tal discussão tem sido renovada quando se trata de prestação de serviços prisionais, no que diz respeito ao cumprimento da execução de pena de pessoas privadas de liberdade. Tema que vem ganhando amplitude no Brasil, principalmente a partir do final da década de 90 , quando da implantação da primeira experiência do modelo de gestão e operação prisional privada no Estado do Paraná (CABRAL; AZEVEDO, 2012).

Apesar da nova roupagem na prestação de serviços públicos, a retirada do Estado da execução de algumas atividades e o consequente repasse à particulares mediante parcerias, concessões ou permissões, não o isenta de sua obrigação com a sociedade, nem tão pouco no desenvolvimento de mecanismos de fiscalização e regulação (MORAES NETO, 2002). O novo papel do Estado apresenta-se não mais 
como mero produtor de utilidades públicas, mas assume atribuição de mediador de interesses econômicos e sociais.

Não obstante essa realidade, as formas organizacionais de agentes privados na provisão de operações prisionais têm se destacado sob o prisma da exploração de serviços, por meio dos modelos de privatização completa, nos moldes do modelo estadunidense em que as empresas privadas podem construir e gerir as prisões e todas as operações necessárias ao funcionamento da unidade penal, cobrando do governo um valor por interno pelos serviços prestados, como segurança, assistência e reinserção social, etc. Outro processo é a delegação parcial dos serviços, também chamados de cogestão, gestão mista ou compartilhada, a exemplo do modelo francês, no qual as funções de direção e vigilância permanecem com o Estado e as outras atividades são transferidas ao ente privado. Diversamente do modelo estadunidense, no modelo francês, terceiriza serviços e o Estado mantém o controle da unidade prisional. A exemplo do modelo francês, alguns estados brasileiros, como Paraná, Bahia e Ceará, passaram a transferir a operação dos estabelecimentos penais à empresas privadas (CABRAL, 2006).

O uso desses novos modelos de gestão prisional se apresenta justificados, pela situação calamitosa da quase totalidade das penitenciárias brasileiras. Ferreira (2012) afirma que o que foi idealizado pelo Estado para reprimir o agente do delito e ao mesmo tempo reeducá-lo para a sociedade se mostra ineficaz. A prova disso são as frequentes violações à Constituição Federal e à Lei de Execuções Penais - LEP, quanto aos direitos ali positivados, a exemplo da ausência ou da deficiente prestação à saúde, à educação, à higiene etc. Cenário esse contraditório às novas formas de gerenciamento da Administração Pública que prega a eficiência dos serviços, tanto no sentido de buscar economia financeira, como a uma gestão voltada para resultados. Entretanto, a estrutura carcerária insuficiente implica no desrespeito aos princípios administrativos e ao interesse público.

Nessa perspectiva, atrelada as transformações estruturais nas funções dos governos, a transferência da gestão prisional, no caso do Rio Grande do Norte, especificamente, vem sendo objeto de discussão de alternativas que repousam além das condições citadas, mas também em outros fatores amplamente influenciados por acontecimentos marcantes, principalmente ocorridos nos anos de 2015 a 2017, como o alto índice de foragidos, 683 entre os anos de 2015 a março de 2017, a 
expansão das facções criminosas "Sindicato do Crime do RN", bem como o nacionalmente conhecido Primeiro Comando da Capital - PCC. Ambos determinaram comandos de ataques a ônibus, organizações públicas e a operadores da segurança, e o que se tem presenciado são os efeitos indesejáveis da prisão, até então restritos aos muros do cárcere, se espalhando pela sociedade a ponto de interferir na vida cotidiana de Natal e de todo o Estado.

Em via paralela, a declaração de estado de calamidade do Sistema Prisional, por meio do Decreto $n^{\circ} 25.017$ de 16 de março de 2015, o qual já foi renovado por duas vezes pelos Decretos $n^{\circ} 25.508$ de 15 de setembro de 2015 e o 26.350 de 14 de setembro de 2016.

Tais acontecimentos afirmam que a ausência de possibilidade de recuperação do internado tem elevado expressivamente a violência, a qual atinge o meio social. Assim discussões circulam em torno de que a hostilidade que extrapola os muros das cadeias é fruto do deficitário modelo de gestão prisional adotado no Rio Grande do Norte.

Ressalta-se ainda que a ascensão da criminalidade disseminadas dentro e fora dos cárceres, influem em mais gastos com segurança e saúde, pelo fato da necessidade de maior policiamento e atendimento hospitalares a aqueles vitimados pelo crime. Sendo assim, o recurso que deveria ser utilizado em outras áreas é destinado para remediar os efeitos da má administração das prisões pelo poder público (FERREIRA, 2012).

A conjuntura do Sistema Penitenciário do Rio Grande do Norte se assemelha ao contexto do resto do país e, por isso, surge a proposta de inovações gerenciais, como o repasse da gestão das maiores penitenciárias do Estado à iniciativa privada. Sob a alegação de combater as mazelas carcerárias em um período de restrições orçamentárias, seria esta uma alternativa para barrar as frequentes rebeliões e fugas que vêm ocorrendo, bem como amenizar o problema da superlotação e falta de estrutura mínima para o atendimento dos direitos e garantias dos apenados.

Nessa perspectiva, entende a Administração Pública que delegar a particulares a gestão da coisa pública, em algumas áreas dos serviços prestados nas unidades prisionais, seria uma alternativa para sanar a precariedade das prisões. 
No atual quadro norte-rio-grandense, em que o discurso governamental é a escassez de recursos para a garantia dos direitos sociais, reacende a discussão na sociedade e vem à tona o seguinte questionamento objeto de paper: de que maneira esse novo modelo de gestão pode contribuir para uma melhor eficiência do Sistema Prisional?

Em busca de responder a esse questionamento e lançar mão do debate que por hora está na agenda do governo, o presente artigo é estruturado da seguinte maneira: primeiramente, trata da política pública prisional e a participação e envolvimento de alguns atores na construção e implementação dessa política; segundo, busca conceituar cogestão apresentando seus limites e contribuições; terceiro, discorre sobre o Sistema Penitenciário do RN e o modelo de gestão idealizado para o desenvolvimento da política prisional e por fim são apresentadas algumas considerações finais.

\section{POLÍTICA PÚBLICA PRISIONAL E O ENVOLVIMENTO DE SEUS ATORES NO PROCESSO DE IMPLEMENTAÇÃO}

A construção de políticas públicas é o ato de operar do Estado e tem como ponto de partida o envolvimento de uma diversidade de interesses, de instituições e de atores que estão inseridos dentro e fora da estrutura Estatal (VIANA, 1996).

A inter-relação entre essas variáveis é ponto primordial no processo decisório inerente à elaboração e implementação de políticas públicas em qualquer setor social, porque permite identificar as influências que a política pública sofre em suas várias etapas, desde a construção da agenda até a sua fase de avaliação.

O percurso da política é permeado de intenções e ações as quais permite um contínuo processo de reflexão, comum a rotina pública. Trata-se na verdade da complexa relação entre o meio social, político e econômico que envolve atores governamentais e não-governamentais (VIANA, 1996).

A formulação de políticas públicas nas diversas áreas parte da premissa da construção de uma agenda de intenções e que percorre as etapas de formulação, implementação e avaliação. A agenda é definida em três tipos: a sistêmica ou não governamental, a governamental e a de decisão. A primeira lista uma gama de assuntos que estão há anos na pauta do governo, mas que não têm um grau 
prioritário; a segunda, são problemas que despertam a merecida atenção governamental; e por fim, a terceira que se encontra na pauta de prioridades de questões que devem ser resolvidas (VIANA, 1996).

Mas como elencar, diante de tantos problemas sociais, o que é mais ou menos importante para entrar na agenda. Sobre essa discussão afirma-se que um assunto para sair da esfera sistêmica e entrar no campo da agenda governamental necessita ser definido como um problema dramático ou de aspecto crítico (VIANA, 1996).

Ainda na ceara da construção da agenda governamental a de se destacar duas peças: os participantes ativos, formados por entes governamentais e nãogovernamentais; e os processos, relacionado a forma de atuação da política na instituição. O grupo governamental engloba pessoas políticas, funcionários de carreira do congresso, parlamentares; o grupo não-governamental abrange os núcleos de pressão, formados por acadêmicos, partidos políticos, mídia, sindicatos, pesquisadores, sociedade civil etc. Ambos têm influência preponderante da formação da agenda. A segunda variável, o processo, especifica as instituições, órgãos e todo o aparelhamento ligado à produção da política pública.

Sendo assim, o conjunto de todas essas variáveis determina a escolha do problema para que nele incida a atuação de uma política pública a qual busca a resolução da demanda posta. Além da seleção do problema é preciso haver viabilidade técnica e a aceitação dos diversos grupos envolvidos, nessa relação entre o meio social e o processo governamental, para que justamente o consenso tenha força e, posteriormente, não se torne uma política fragmentada pelo dissenso e, por sua vez, cause instabilidade conjuntural.

Nesse diapasão a elaboração das políticas públicas voltadas ao Sistema Prisional, exige um olhar peculiar e abordagem distinta de outras áreas sociais, como educação e saúde, por exemplo. Nestas se veem resultados individuais, quando há disponibilidade de vaga na escola ou de um leito no hospital (ALLANIC, 2008). No sistema penitenciário, no entanto, seus efeitos se dão de forma coletiva, em condições iguais para todos. Além disso, merece destaque pelo envolvimento de diversos atores; e também pela relevância política, visto que nas últimas décadas os prejuízos causados a segurança pública também se originam da má gestão dos 
presídios, sejam por decisões de governantes ou imposições de normas que tentam regrar o sistema.

Sendo assim, é evidente que a política penitenciária necessita de reconhecimento enquanto política pública independente, não vista como um subsistema das polícias, mas sim organizada para o uso de instrumentos modernos de governança, abandonando modos arcaicos de cultura organizacional baseadas na burocracia da gestão prisional e na repressão dos indivíduos encarcerados.

A política prisional foi idealizada para ser um arcabouço de oportunidades para o indivíduo submetido à privação de liberdade. Por força da lei, as medidas de ressocialização, como ofertas de estudos e capacitação profissional, cuidados com a saúde física e mental do preso, bem como o direito à convivência familiar, são mecanismos que colaboram ao retorno social (ALLANIC, 2008).

Desse modo deve ser desenvolvida em consonância com a Lei de Execução Penal, a qual afirma em um de seus objetivos previsto no $1^{\circ}$ artigo que "A execução penal tem por objetivo efetivar as disposições de sentença ou decisão criminal e proporcionar condições para a harmônica integração social do condenado e do internado" (BRASIL, 1984, p.1). Com isso, a execução da pena não tem somente o caráter punitivo, mas também humanizador e integrador.

Outros instrumentos legais buscam uniformizar o conjunto de políticas públicas hoje existentes no sistema prisional, conforme o quadro a seguir:

Quadro 1 - Principais resoluções que regulamentam o sistema penitenciário no Brasil.

\begin{tabular}{|l|l|}
\hline \multicolumn{1}{|c|}{ Regramento } & \multicolumn{1}{c|}{ Objetivo } \\
\hline Resolução $n^{\circ} 14$ de 11 de novembro de 1994. & $\begin{array}{l}\text { Fixa as regras mínimas de tratamento para o } \\
\text { preso no Brasil }\end{array}$ \\
\hline Resolução $n^{\circ} 03$ de 11 de março de 2009 & $\begin{array}{l}\text { Regulamenta a oferta de educação nos } \\
\text { estabelecimentos prisionais }\end{array}$ \\
\hline Resolução $n^{\circ} 04$ de 29 de junho de 2011 & Assegura o direito à visita intima à pessoa presa \\
\hline Resolução $n^{\circ} 09$ de 18 de novembro de 2011 & $\begin{array}{l}\text { Estabelece diretrizes para elaboração de } \\
\text { projetos, construção, reforma e ampliação das } \\
\text { unidades prisionais }\end{array}$ \\
\hline
\end{tabular}

Fonte: Criado a partir das Resoluções $n^{\circ} 14$ de 11/11/94, $n^{\circ} 03$ de 11/03/09, $n^{\circ} 04$ de 29/03/11 e $n^{\circ}$ 09 de 18/11/11.

Ainda, o Plano Nacional de Política Criminal e Penitenciária, reelaborado a cada quatro anos pelo Conselho Nacional de Política Criminal e Penitenciária, institui o modelo de política para o sistema penitenciário, como, por exemplo, medidas que buscam a integração social dos egressos, tendo como base a 
assistência educacional e profissionalizante, visando a diminuição da reincidência criminal; a implantação da política de saúde mental, a defensoria pública plena, etc. Tais medidas se de fato fossem efetivadas já dariam uma nova roupagem a gestão atual do sistema penitenciário.

Entretanto, longe de ser o que preconiza a Lei de Execução Penal e todos os instrumentos legais mencionados e outros existentes, as prisões, em geral, não têm ou são mal estruturadas de oficinas de capacitação, escolas improvisadas, atendimento psicológico e social mal aparelhados e, por fim, inexistência total de opções de cultura e lazer (ALLANIC, 2008). Logo, as prisões dispõem de ambiente pouco favorável a melhoria do comportamento social do indivíduo encarcerado.

Associado a esse fato, é claro que a política prisional em seu processo de implementação não só depende de estrutura adequada, necessita muito mais da atuação de servidores envolvidos no processo, em consonância com as diretrizes de tal política.

As ações ou programas de (re)integração do preso ao meio social promovidas nos estabelecimentos prisionais são ferramentas que diminuem a possibilidade de reincidência criminal. Contudo, as oficinas de capacitação profissional, atendimentos médicos e psicológicos e o acompanhamento familiar não serão suficientes caso os servidores prisionais envolvidos no processo, não sejam participantes no sentido de visualizar tais ações e programas como integrantes do seu trabalho no cumprimento da execução penal (ALLANIC, 2008).

Para explicar melhor, é preciso entender que os servidores do sistema penitenciário, fala-se aqui especificamente do agente penitenciário, tem sua formação profissional voltada prioritariamente aos parâmetros policiais e, por isso, ao uso da força e do porte de arma. A construção de uma visão repressiva em detrimento de uma visão mais orgânica e integrada com os servidores da (re)integração social (psicólogos, médicos, educadores, etc.), pode contribuir para que o preso tenha comportamentos e tendências violentas dentro da prisão e quando sair dela.

Além disso, a política prisional também deve ser enxergada como um círculo de cooperação entre os órgãos governamentais da segurança pública, vale dizer policias militares e civil e os órgãos do Poder Judiciário, à medida que o sistema carcerário faz parte de uma estrutura cíclica, e não de uma instituição secundária, o 
ponto final da política pública de segurança. Essa visão arcaica de que a prisão é o fim do ciclo de segurança pública retroalimenta a criminalidade quando não se valoriza um sistema integrado de órgãos, instituições, comandos e ações que devem seguir diretrizes previamente definidas. Uma gestão pública articulada e de forma inter dependente com os demais segmentos seria um caminho eficiente e coerente, para a eficácia da ação de ressocialização do apenado.

\section{COGESTÃO: LIMITES E CONTRIBUIÇÕES}

Os modelos prisionais com participação privada existentes, a exemplo da modalidade americana e francesa, são os de privatização total e cogestão. Este último, como assim é chamado pelos defensores brasileiros do modelo francês de gestão das prisões, vai na mesma vertente da busca de alternativas para a provisão dos serviços públicos tradicionais. Os defensores desse modelo fundamentam seus argumentos nas limitadas fontes de financiamento, melhoria da qualidade dos serviços, bem como na necessidade de diminuir custos operacionais (COSTA, 2008).

Já no modelo de privatização, seguido nos Estados Unidos, é permitido a privatização em sua totalidade, abrangendo desde a construção dos presídios, da assistência material até a execução da pena propriamente dita (SILVA, 2016).

Em 1992 o Conselho Nacional de Política Criminal e Penitenciária, propôs a implementação da privatização dos presídios no Brasil, por meio da Resolução $n^{\circ} 1$ de 24 de março de 1993. Contudo, no ano de 2002 foi publicado uma nova resolução que tratava sobre a proibição da privatização no país, mas permitia que os serviços que não fossem ligados à segurança, à administração e ao gerenciamento da unidade, bem como à disciplina e ao acompanhamento da individualização da execução penal pudessem ser executados por empresa privada (ROSATO, 2015).

Ao analisar o sistema penitenciário brasileiro é possível verificar que está em dissonância com a Lei de Execução Penal e as garantias estabelecidas na Constituição. A Administração Pública demostra descompasso entre a execução dos serviços prisionais e a legislação, fatores esses responsáveis pelo alto índice de reincidência criminal. $O$ resultado é a descrença da sociedade no processo de execução penal. Assim como diz Rosato $(2015$, p. 2$)$ "não é possível que o apenado 
seja tratado como um animal no interior da carceragem e esperar que ele haja como ser humano quando retornar à sociedade".

Segundo o Conselho Nacional de Justiça, o sistema prisional passa por uma crise a muito tempo, com infraestrutura precária e superlotação, fazendo com que as penas aplicadas aos infratores não cumpram a sua função retributiva e preventiva (ANTUNES, 2017).

Em virtude disso já é realidade em vários estados brasileiros a experiência de delegar atividades meio, executadas nas unidades prisionais à iniciativa privada. Com o argumento de atender aos ditames constitucionais, individualizar a pena, diminuir custos e a superlotação das penitenciárias (OLIVEIRA, 2002), a chamada terceirização dos serviços prisionais, segundo o qual a empresa contratada é responsável pela manutenção do estabelecimento, alimentação, assistência material, social, jurídica, médica, psicológica, educacional, ensino profissionalizante, contratação do corpo de funcionários de segurança e disciplina, técnicos e administrativo, entre outros; enquanto a outra parcela da execução penal, o cumprimento da pena propriamente dita, ficaria sob a égide do poder público, o Estado é responsável pela construção do prédio e pela direção da unidade: diretor geral, vice-diretor e chefe de segurança. Por exigência da LEP, esse é um dos limites da cogestão, o Estado deve manter o comando da direção e da segurança do presídio, conforme preceitua o artigo 47 "o poder disciplinar na execução da pena privativa de liberdade, será exercido pela autoridade administrativa conforme as disposições regulamentares" (BRASIL, 1984). Uma vez que a legislação proíbe a delegação de funções jurisdicional, do exercício do poder de polícia e outras atividades exclusivas do Estado.

Confirmando esse posicionamento, Mirabete (1993) citado por Costa (2008) detalha que atividade de execução penal se apresenta em dois planos: o jurisdicional e o administrativo, no qual participam o Judiciário e o Executivo, respectivamente. A etapa jurisdicional se refere à aplicação das normas de direito penal e processual penal, enquanto a administrativa desdobra-se nas atividades administrativas-judiciárias, relacionadas à disciplina dos internos e a ordem do estabelecimento prisional; e a outra esfera administrativa, nas atividades de assistência material, social, saúde, educação, jurídico e ao funcionamento da prisão. Segundo o autor, atividade jurisdicional e a atividade administrativa-judiciária não 
podem ser delegadas a operadores não ligados ao Poder Público, por tratar-se do direito de punir, o que é exclusivo do Estado. Já na atividade de assistência material e gestão da prisão, estas podem ser objeto de delegação, justamente por não haver previsão legal que impeça a sua execução pelo ente privado.

Esse tipo de gestão é feito por meio de contrato administrativo, firmados posteriormente a processos licitatórios, o que é legalmente possível.

A exemplo disso o Estado do Paraná inaugurou em 1999 esse modelo de gestão no país com a Penitenciária Industrial de Guarapuava. Em 2001, o Ceará aderiu a experiência de terceirização dos serviços prisionais. Depois vieram Bahia, Amazonas, Santa Catarina e Espirito Santo, totalizando em 2009, 1\% da população carcerária de todo país (CABRAL; AZEVEDO, 2012).

Passadas quase duas décadas da implantação da primeira experiência de gestão terceirizada no país, ainda são praticamente desconhecidos os aportes dessa modalidade de gestão não-estatal, pela insuficiência de estudos mais aprofundados que considerem indicadores de desempenho.

Embora se destaque pontos incomuns nas experiências acima mencionadas, não são exemplos homogêneos em que se pode extrair conclusões pacíficas sobre as contribuições benéficas que esse modelo de gestão trouxe a administração das prisões. Apenas é possível afirmar que todas se mostram atentas com o atendimento de serviços e atividades voltados a reintegração social, em virtude da maior oferta de serviços aos internos. Nessa perspectiva o relatório do Conselho Nacional de Política Criminal e penitenciária, ao comparar a Penitenciária Industrial de Joinville com os demais estabelecimentos prisionais do estado de Santa Catarina diz o seguinte:

\footnotetext{
Essa unidade revela um cenário industrial diferente das anteriores, embora haja problemas, eles são de proporção menor e podem ser corrigidos com facilidade. Comprova-se com a experiência da Penitenciária Industrial de Joinville que fazer diferente é possível, que os resultados são muito melhores para a sociedade e para os indivíduos, para isso é necessário gerir melhor os recursos e trabalhar de forma planejada, coesa e interdisciplinarmente (CNPCP, 2010, p. 38).
} 


\section{A REALIDADE CARCERÁRIA NORTE-RIOGRANDENSE E O MODELO DE GESTÃO IDEALIZADO.}

A realidade carcerária mostra cada vez mais a urgência de implementação de políticas públicas eficazes e eficientes para o sistema prisional. Segundo Departamento Penitenciário Nacional (2014), entre os anos de 1990 e 2014 a população carcerária no país aumentou 6,7 vezes, passando de 90 mil pessoas presas para 607 mil. Observa-se também altos índices de reincidência dos egressos do sistema prisional, aumento dos níveis de encarceramento sem impacto na redução da violência, além da ampliação gradual em investimentos na política criminal e penitenciária, sem, porém, resultar em melhoria na segurança pública.

Os dados atualizados em março de 2017, de acordo as informações prestadas pela Seção de Inteligência e Informação Penitenciária do RN é de que Estado do Rio Grande do Norte possui uma população carcerária de 8.127 presos, sendo 7.635 do sexo masculino e 492 do sexo feminino. Estão distribuídos nos seguintes regimes: fechado com 3.173 detentos, semiaberto com 1.129, aberto com 829 , provisório com 2.996, sob medida de segurança há 46 deles, além daqueles custodiados pela Secretaria de Segurança Pública, sob responsabilidade da polícia civil. O número de vagas existentes no sistema prisional corresponde a 4.326, o que representa um déficit de 3.801 vagas, ou seja, o Sistema Penitenciário do RN possui pouca mais da metade de vagas necessárias para comportar sua população. Além disso, rebeliões, fugas, violência internas são eventos corriqueiros que têm piorado a realidade prisional do estado.

Em janeiro de 2017, ocorreu a maior crise do sistema penitenciário já registrada no RN. O conflito na Penitenciária Estadual de Alcaçuz entre duas facções rivais (Sindicato do RN e PCC) deixou 26 mortos, além de causar a destruição de todo o presídio.

"Isso se dá pela incapacidade estatal em administrar todos os estabelecimentos prisionais, bem como pelo descaso político para com certa parcela da sociedade" (GOMES; SILVA, 2016, p. 4). O fato de não se garantir as condições mínimas de saúde, higiene, auxílio moral e material, infraestrutura, causa reincidência criminal e consequente gastos reiterados com novos processos e novas custodias. 
Diante disso a situação carcerária do RN parece não considerar os requisitos básicos impostos pela lei. A ausência de estrutura, de serviços adequados, e de recursos humanos para $\mathrm{o}$ trato com $\mathrm{O}$ detento dificulta bastante $\mathrm{o}$ processo (re)integrador. Associado a isso as tendências de crescimento de indivíduos reclusos e o déficit de vagas reflete sobremaneira no recrudescimento das políticas penitenciárias. E assim as condições atuais das prisões do RN intrica o alcance dos objetivos da LEP, o qual é proteger a sociedade e proporcionar ao custodiado um ambiente reintegrador para o retorno ao convívio social.

A Lei de Execução Penal em seu capítulo II - Da Assistência, preceitua o seguinte: "a assistência ao preso e ao internado é dever do estado, objetivando prevenir e orientar à convivência em sociedade". A LEP ainda reitera em seu artigo 22 que "a assistência social tem por finalidade amparar o preso e internado a prepará-los para o retorno à liberdade". Dessa maneira é evidente a responsabilidade do Estado no processo punitivo e (re)integrador do preso.

O modelo de cogestão idealizado pelo governo do Estado do RN, a fim de amenizar o caos prisional do estado, segue o modelo similar ao aplicado na França, por meio da terceirização dos serviços operacionais, sendo de responsabilidade do Estado direção e segurança do presídio, ou seja, a unidade é administrada tanto pelo Estado quanto pelo setor privado.

Apesar de a cogestão se apresentar como uma maneira de promover eficiência, agilidade e desburocratizar os serviços prisionais, a adesão a essa nova modalidade de gestão dos presídios do RN iria onerar do Estado, o que vai de encontro com a realidade financeira do $\mathrm{RN}$, ao contrário do que prega esse modelo que é a desoneração do erário público.

Assim não se pode ignorar o impacto econômico que essa modalidade de administração traria as finanças do RN, o Estado entraria em situação orçamentária insustentável e não atenderia ao interesse público.

\section{CONSIDERAÇÕES FINAIS}

Diante de tudo que foi exposto, mostra-se a vulnerabilidade administrativa do Estado em gerir as unidades prisionais, assegurar aos detentos o cumprimento da pena visando os objetivos da retribuição, prevenção e (re)integração, tornando 
assim, inalcançável a meta da reabilitação. Em virtude desse contexto os serviços de terceirização prisional veem ganhando amplitude como modelo "salvador" para o caos penitenciário.

Para formulação de políticas públicas no sistema prisional não basta pautarse nas convicções ideológicas dos participantes das discussões, mas também em dados concretos de análises comparativas entre as formas tradicionais e as formas híbridas de execução de serviços para que se possa tomar conhecimento das fragilidades e potencialidades de cada forma de gestão e suas implicações na implementação, com fins de montar uma estrutura de governança adequada a complexa realidade das prisões.

O que se tem na maioria das vezes, são argumentos pautados na subjetividade de ativistas que optam pelo sim ou pelo não da gestão privada, argumentando pela superioridade qualitativa dos serviços prestados pela empresa privada em contrapartida a ineficiente ingerência do governo. Por outro lado, os defensores da gestão exclusivamente pública alertam para o interesse lucrativo das entidades privadas em manter a clientela e, de forma mais especulativa, na participação indireta de grupo criminosos na gestão das unidades prisionais. Apesar dos argumentos lógicos, não se pode limitar apenas a realidade observada, ou simplesmente aderir um posicionamento radical. É preciso ter a formulação de dados concretos e científicos, para assim, montar uma base de informações sólidas que possam subsidiar a melhor forma de gestão.

Pelas experiências terceirizadas espalhadas pelo país tomadas como exemplo, elas mostraram-se, em geral, mais eficientes e eficazes quando comparadas a forma de provisão tradicional. Isso se deve, principalmente porque apresentaram melhor qualidade dos serviços prestados aos internos e também maior capacidade de controle e decisão, flexibilidade de alocação de pessoal para as atividades, maior estrutura de incentivos, proporcionado mais celeridade as demandas institucionais.

Assim, em relação aos operadores privados, por menores que sejam as ações empreendidas, estas se tornam sempre melhores do que as ações executadas pelo governo, visto as restrições institucionais que há nas formas tradicionais de serviços quando comparadas as duas modalidades de gestão, a forma terceirizada sempre será superior a qualidade do serviço do entre público. 
Sendo assim, o sucesso da administração penitenciária não está ligada somente ao modelo de gestão adotado, está diretamente relacionada a legislação penal, ao desempenho do Poder Judiciário e do Ministério Público, cuja morosidade pode afetar o cotidiano das prisões, está relacionado as políticas que disponibilizem investimentos ao setor para a criação de vagas, geração de ambientes e atividades de profissionalização, educativas, serviços de assistência à saúde, judiciária, material, religiosa etc., aumento no quantitativo de servidores condizentes com o número de internos, separação dos presos por tipo de delito e reincidência criminal; influência de atores políticos (deputados, senadores, governadores etc.), instituições organizadas da sociedade civil (sindicatos, igrejas, ONG's).

Portanto, o que se defende é um modelo de gestão pública com toda a capacitação operativa igual a ofertada pelo ente privado. Se o Estado pode dispor de recurso para manter a prestação de serviço terceirizado, tal investimento deverá ser destinado para o custeio das atividades de execução pelo ente público, com práticas interventivas em busca de resultados previamente planejados, buscando da mesma forma garantir o princípio constitucional da eficiência. Do mesmo modo, poder de fiscalizador que o Estado exerceria sob o particular seria recíproco nos estabelecimentos exclusivamente estatais.

Saliente-se que dessa maneira o benefício é revertido para a própria sociedade, uma vez que o sucesso no processo de recuperação acarreta a diminuição da taxa de criminalidade.

\section{REFERÊNCIAS}

ANTUNES, Matheus Gonçalves; MARCONI, André Luís da Costa Baptista; FREITAS, Renato Alexandre da Silva. A "Privatização" do Sistema prisional como forma de garantir a ressocialização dos encarcerados. Revista Juris UniToledo, Araçatuba, SP, v. 2, n. 1, p. 128-138, jan./mar. 2017.

ALLANIC, Louis. Políticas Públicas de Segurança: a questão do sistema prisional. CSOnline. Revista Eletrônica de Ciências Sociais, a. 2, v. 4, ago. 2008.

AZEVEDO, Afonso Henrique Cardoso de. Sistema Prisional Brasileiro. Revista Científica da Unesc, v. 13, n. 16, 2015.

BRASIL. Ministério da Justiça. Levantamento nacional de informações penitenciárias: Infopen, jun. 2014. Brasília: Depen, 2014. 
. Ministério da Justiça. Plano Nacional de Política Criminal e

Penitenciária. Brasília: Conselho Nacional de Política Criminal e Penitenciária. 2015.

. Departamento Penitenciário Nacional. Levantamento Nacional de informações penitenciárias: INFOPEN, jun. 2014. Brasília: Ministério da Justiça, 2014.

. Lei de Execução Penal. Lei nº 7210 de 11 de julho de 1984.

. Resolução $n^{\circ}$ 14, de 11 de novembro de 1994. Resolve fixar as regras mínimas para o tratamento do preso no Brasil. Publicada no Diário Oficial da União de 02 dez. 1994.

Resolução n $^{\circ} 03$ de 11 de março de 2009. Resolve estabelecer diretrizes nacionais para a oferta de educação nos estabelecimentos penais de todo o Brasil. Publicada no DOU de 25 mar. 2009, Seção 1, p. 22-23.

. Resolução $n^{\circ}$ 09, de 18 de novembro de 2011. Resolve editar as Diretrizes Básicas para Arquitetura Penal. Publicado no DOU, n. 222, 21 nov. 2011, Seção 1.

. Resolução $n^{\circ}$ 04, de 29 de junho de 2011. Recomenda aos Departamentos Penitenciários Estaduais ou órgãos congêneres seja assegurado o direito à visita íntima a pessoa presa, recolhida nos estabelecimentos prisionais. Publicada no DOU de 05 abr. 1999, Seção 1.

CABRAL, Sandro; LAZZARINI, Sérgio G. Impactos da participação privada no sistema prisional: evidencias a partir da terceirização de prisões no Paraná. RAC, Curitiba, v. 14, n 3, p. 395-413, maio/jun. 2010.

; AZEVEDO, Paulo Furquin de. Terceirização de prisões: notas de uma análise comparada. In: COELHO, Maria Thereza Ávila Dantas; CARVALHO FILHO, Milton Julio de (Org.). Prisões numa abordagem interdisciplicar. Salvador: EDUFBA, 2012. p 53-71.

COSTA, Lídia Mendes da. O Sistema Prisional Brasileiro e a ressocialização do preso na parceria, terceirização e privatização. Presidente Prudente, 2008.

FERREIRA, Paula Guimarães. A estrutura do sistema prisional brasileiro frente aos objetivos da teoria da pena. In: Âmbito Jurídico, Rio Grande, v. 15, n. 103, ago. 2012. Disponível em: <http://www.ambitojuridico.com.br/site/ ?n_link=revista_artigos_leitura\&artigo_id=12093>. Acesso em: jan. 2017.

GOMES, Magno Frederici; SILVA, Fábio Márcio Filó. Meio ambiente carcerário, sustentabilidade e as Parcerias público-privadas. Revista da Universidade Vale do Rio Verde, Três Corações, v. 14, n. 2, p. 1021-1033, ago./dez. 2016. 
LIRA, Anderson Gabriel Rocha. Reincidentes Criminais no Cotidiano Prisional do Centro de Detenção Provisória da Ribeira - Natal/RN. Trabalho de conclusão de curso (Graduação) - Departamento de Políticas Públicas da Universidade Federal do Rio Grande do Norte, 2013.

MORAES NETO, Floriano de. A nova regulação dos serviços públicos. Revista de Direito Administrativo, Rio de Janeiro, v. 228, p. 13-29, abr./jun. 2002.

OLIVEIRA, Edmundo. 0 futuro alternativo das prisões. Forense: Rio de Janeiro, 2002.

PRADO, Leandro Machado Avener. Presos ainda controlam ala de presídio no RN apesar da presença da polícia. Disponível em: <http://www1.folha.uol.com.br/ cotidiano/2017/01/1850276-presos-ainda-controlam-ala-de-presidio-no-rn-apesar-dapresenca-da-policia.shtml>. Acesso em: jan. 2017.

RIO GRANDE DO NORTE. Decreto n² 25.017 de 16 de março de 2015. Declara estado de calamidade, abrangente exclusivamente do Sistema Penitenciário do Estado do Rio Grande do Norte, para o fim de legitimar a adoção e execução de medidas emergenciais que se mostrarem necessárias ao restabelecimento do seu normal funcionamento. Diário Oficial, Natal, RN, 17 mar. 2015.

. Decreto $n^{\circ} \mathbf{2 5 . 5 0 8}$ de 15 de setembro de 2015. Prorroga, por mais 180 (cento e oitenta) dias, o estado de calamidade, abrangente exclusivamente do sistema Penitenciário do Estado do Rio Grande do Norte, para o fim de legitimar a adoção e execução de medidas emergenciais que se mostrarem necessárias ao restabelecimento do seu normal funcionamento. Diário Oficial, Natal, RN, 16 set. 2015.

Decreto $n^{\circ} \mathbf{2 6 . 3 5 0}$ de 14 de setembro de 2016. Prorroga, por mais 180 (cento e oitenta) dias, o estado de calamidade, abrangente exclusivamente do Sistema Penitenciário do Estado do Rio Grande do Norte, para o fim de legitimar a adoção e execução de medidas emergenciais que se mostrarem necessárias ao restabelecimento do seu normal funcionamento. Diário Oficial, Natal, RN, 15 set. 2016.

SILVA, Cássia Neves. Privatização dos Presídios e sua aplicabilidade no sistema penitenciário brasileiro. Revista Juris Rationis, a. 9, n. 1, p. 77- 85, out. 2015./mar. 2016.

ROSATO, Larissa. A privatização dos presídios como mecanismo de funcionamento da execução penal. Revista Univem. $1^{\circ}$ Simpósio de Constitucionalismo, Democracia e Estado de Direito.

VIANA, Ana Luiza. Abordagens Metodológicas em Políticas Públicas. RAP, Rio de Janeiro, v. 30, n. 2, p. 5-43, mar./abr. 1996.

\section{Artigo recebido em: 27/05/2017}

Artigo aprovado em: 11/08/2017 